\title{
Behavioural responses of reptile predators to invasive cane toads in tropical Australia
}

\author{
DAVID J. PEARSON,${ }^{1}$ JONATHAN K. WEBB,,${ }^{2,3}$ MATTHEW J. GREENLEES, ${ }^{2}$ \\ BENJAMIN L. PHILLIPS, ${ }^{2,4}$ GAVIN S. BEDFORD, ${ }^{5}$ GREGORY P. BROWN, ${ }^{2}$ \\ JAI THOMAS ${ }^{2}$ AND RICHARD SHINE ${ }^{2 \star}$ \\ ${ }^{1}$ Department of Parks and Wildlife, Perth, Western Australia, Australia, ${ }^{2}$ Biological Sciences A08, \\ University of Sydney, Sydney, NSW 2006, Australia (Email: rick.shine@sydney.edu.au), ${ }^{3}$ School of the \\ Environment, University of Technology Sydney, Sydney, New South Wales, ${ }^{4}$ School of Marine and \\ Tropical Biology, Fames Cook University, Townsville, Queensland, and ${ }^{5}$ Crocosaurus Cove, 58 Mitchell \\ Street, Darwin, Northern Territory, Australia
}

\begin{abstract}
The ecological impact of an invasive species can depend on the behavioural responses of native fauna to the invader. For example, the greatest risk posed by invasive cane toads (Rhinella marina Bufonidae) in tropical Australia is lethal poisoning of predators that attempt to eat a toad; and thus, a predator's response to a toad determines its vulnerability. We conducted standardized laboratory trials on recently captured (toad-naïve) predatory snakes and lizards, in advance of the toad invasion front as it progressed through tropical Australia. Responses to a live edible-sized toad differed strongly among squamate species. We recorded attacks (and hence, predator mortality) in scincid, agamid and varanid lizards, and in elapid, colubrid and pythonid snakes. Larger-bodied predators were at greater risk, and some groups (elapid snakes and varanid lizards) were especially vulnerable. However, feeding responses differed among species within families and within genera. Some taxa (notably, many scincid and agamid lizards) do not attack toads; and many colubrid snakes either do not consume toads, or are physiologically resistant to the toad's toxins. Intraspecific variation in responses means that even in taxa that apparently are unaffected by toad invasion at the population level, some individual predators nonetheless may be fatally poisoned by invasive cane toads.
\end{abstract}

Key words: Bufo marinus, ecological impact, foraging tactics, invasive species, predator-prey interaction.

\section{INTRODUCTION}

Invasive species affect native taxa via a diverse array of mechanisms, and the nature and magnitude of impact can vary not only among species, but even differ dramatically through space and time, as a result of local environmental conditions (Pimentel et al. 2000). Depending on the mechanism of impact, the arrival of an invader can differentially affect size-classes or sexes even within a single population of vulnerable native animals (Webb et al. 2005). As a result, predicting invader impact is fraught with difficulty, even in relatively straightforward cases where the mechanism is well understood. That challenge is exacerbated by the possibility of indirect effects, whereby an invaderinduced change in abundance or behaviour of a native taxon cascades through into impacts on another native, potentially overwhelming any direct impact of the invader on the latter native species (Wootton 1994; Nelson et al. 2010). The complexity of invader effects means that we need to evaluate mechanisms indepen-

${ }^{\star}$ Corresponding author.

Accepted for publication September 2013.

(C) 2013 The Authors

Austral Ecology (C) 2013 Ecological Society of Australia dently of overall (population-level) impact. For example, an invader may have negligible overall impact on populations of a native species either because it has no direct effect, or because strong positive and negative effects cancel each other out (Brown et al. 2011). Distinguishing between these two scenarios may help us to understand the reasons for geographic and temporal variation in invader impacts on threatened native taxa. Thus, we need empirical data on mechanisms of impact, as well as overall population-level responses (i.e. comparisons of faunal abundance pre- and post-invasion).

The invasion of cane toads (Rhinella marina Bufonidae) through tropical Australia has attracted detailed study. The major mechanism of toad impact is lethal toxic ingestion (Shine 2010). Because Australia lacks native bufonids, the distinctive chemical defences (bufadienolides) of toads are rapidly fatal if ingested by many native Australian predators. Thus, invasion of toads has caused massive population-level declines of some predators (Shine 2010; Brown et al. 2011). However, other predator taxa have been unaffected at the population level, perhaps because they do not attempt to consume toads, or rapidly learn not to do 
so, or are physiologically tolerant of the toad toxins (reflecting pre-adaptation through ancestry in a region that contains toads: Llewelyn et al. 2011). Wildlife managers need to predict (or at least, understand) the differential vulnerability of native species, so they can focus conservation efforts on the most highly threatened taxa. This has stimulated several attempts to predict toad impact on native reptile predators. The first such attempt was by Phillips et al. (2003), who relied on the (pre-toad-invasion) dietary habits of native snakes to infer whether or not a snake was likely to attempt to eat toads. Because many snake species eat frogs, they predicted that those that also try to eat toads would be at high risk. Field surveys in the Darwin area several years later suggested that these predictions were in error; several snake species expected to decline had in fact increased in abundance after toad arrival (Brown et al. 2013). One plausible explanation is that survival rates of predators may have been enhanced more by indirect effects (such as toadinduced mortality of apex predators, especially large varanid lizards) than they were reduced by direct (fatal poisoning) effects (Brown et al. 2011). Another possibility is that anuran-eating snakes can distinguish between toads and frogs, and that many frog-eating snakes (and lizards) do not attempt to eat toads even when they are available. The only way to evaluate that alternative hypothesis is to actually expose predators to toads, and see how they react.

Based on this reasoning, we conducted trials where we captured predatory reptiles in advance of the toad invasion, maintained them in captivity, and offered them live (ingestible-size) cane toads. We recorded whether or not the predator attacked the toad, whether or not it ate the toad, and whether or not the predator was killed by toad toxins. For ethical reasons, we performed the work on only small sample sizes, except in cases where the study was part of a larger project on responses of specific taxa (e.g. to quantify selection on behaviour and morphology in death adders, Acanthophis praelongus: Phillips et al. 2010). To further reduce the numbers of animals killed for this component of the work, we primarily used animals that had been collected as voucher specimens during faunal surveys, and were destined for euthanasia and preservation anyway. The resultant small sample sizes reduce our ability to make robust comparisons, but still reveal several interesting patterns that clarify modes of impact of invasive cane toads on reptile predators in tropical Australia.

\section{MATERIALS AND METHODS}

The data in this paper were gathered over several years (2005 to 2009), on animals collected from a range of localities i.e. from Darwin in the Northern Territory (NT) to the Mitchell
Plateau in Western Australia (WA). Collection localities moved westwards as the toad front advanced, such that all specimens were taken from areas not yet invaded by cane toads (and hence, the responses of the predators had not been affected by prior exposure to toads). The basic protocol was to collect reptiles of any species that might attack and consume a cane toad, and bring them back to our husbandry facilities in Darwin (2005 only), or to the Middle Point research station near Darwin (2006 to $2009 ; 131^{\circ} 18^{\prime} 50^{\prime \prime} \mathrm{E}$, $12^{\circ} 33^{\prime} 26^{\prime \prime} \mathrm{S}$ ) where the animals were maintained individually in opaque plastic containers with access to water and shelter. Enclosure sizes depended upon the species concerned, and ranged from $105 \times 105 \times 80 \mathrm{~cm}$ (for the largest lizards and snakes) to $21 \times 12 \times 7 \mathrm{~cm}$ (for the smallest lizards and snakes). The enclosures were kept in an outdoor, shaded building exposed to ambient air temperature and light levels.

Because some reptiles refuse to feed in captivity, we only offered toads to reptiles that were feeding consistently on alternative prey (e.g. native frogs, crickets). An ingestiblesized toad (i.e. body size appropriate for the predator in question) was placed into the predator's enclosure and left for $24 \mathrm{~h}$, after which we recorded the fate (dead or alive) of both toad and potential predator. The toad was then removed, and an alternative prey item provided. Surviving predators were offered toads (and other prey types, alternately) on up to six occasions, after which the animals were humanely euthanized and preserved. Details of our experimental protocols differed through time and among species, depending on factors such as the availability of toad metamorphs of different sizes, and alternative prey, and whether or not the parotoid glands of toads were emptied (by manual pressure) prior to the anurans being offered to the predators.

Statistical analyses of these data were conducted in Statview 5.0 and JMP 9.0 (SAS Institute, Cary, NC, USA). We compared species in terms of the relative numbers of predators ignoring, attacking, consuming and being killed by toads using contingency-table tests. We evaluated interspecific relationships between predator behaviour ( $\%$ of specimens showing each behaviour) and mean body size (mass) per species, using linear regression.

\section{Ethical note}

Conducting trials in which predators are exposed to live prey items raises serious ethical issues, because of the potential suffering involved both by the prey if attacked, and by predators if poisoned by the toxic prey. In this case, the relevant animal ethics committee (University of Sydney Animal Care and Ethics Committee) decided that this suffering was justified by the potential value of the results for conservation and management. As noted above, we minimized the ethical problems by restricting the study to small sample sizes, to animals collected immediately in advance of the toad invasion front (i.e. from populations that would have soon encountered live toads in the field), and by using animals that had been taken as voucher specimens in pre-toad-invasion faunal surveys, as part of population-level monitoring studies of toad impact (and hence, were scheduled to be euthanized immediately). In practice, suffering was minor; prey animals seized by predators typically were killed almost instantly, and

(C) 2013 The Authors

Austral Ecology (C) 2013 Ecological Society of Australia 
predators poisoned by cane toads died of cardiac failure as soon as they ingested (or in some cases, mouthed) the toad. Although we monitored enclosures to detect and humanely euthanize any animals that were severely affected but not killed by encounters, no such events were recorded and thus, we did not need to intervene.

\section{RESULTS}

We obtained data on the behavioural responses of 252 snakes (136 elapids, belonging to 10 species; 81 colubrids, belonging to 4 species; and 35 pythons, belonging to 3 species) and 206 lizards (120 scincids, belonging to 12 species; 23 agamids, belonging to 8 species; 1 pygopodid; and 62 varanids, belonging to 9 species). Overall, reptile predators attacked toads in about half of the trials, both in snakes (elapids $52 \%$, colubrids $52 \%$, pythons $57 \%$ ) and lizards (skinks $10 \%$, agamids $11 \%$, pygopodid $0 \%$, varanids $74 \%$ ). Predators were killed by ingesting toad toxins in $21 \%$ of trials (elapids $31 \%$, colubrids $14 \%$, pythons $32 \%$, skinks $3 \%$, agamids $2 \%$, pygopodid $0 \%$, varanids $41 \%)$.

Some broad patterns emerge from the data in Table 1:

1. In all the families that we studied except the sole pygopodid, at least some individuals attacked cane toads, and died as a result. In some cases, predators died soon after they seized a toad, before swallowing it.

2. The frequency of such attacks varied among species (contingency table, $\chi^{2}=133.29, P<$ 0.0001 ), with attacks more frequent by species within some families than others. For example, all elapid species except the ornate snake (Furina ornata) and all of the varanid species except Varanus storri were recorded to attack and kill toads, whereas we recorded attacks on toads by only three of the 13 scincid species and two of the seven agamid species.

3. Species differed not only in whether or not they would attack toads, but also in whether or not such attacks were followed by ingestion of the toad (looking only at predators that attacked toads; $\chi^{2}=60.31,27$ d.f., $P<0.0002$; Table 1). For example, most snakes that attacked toads went on to consume them (e.g. Acanthophis, Enhydris, Pseudechis, Pseudonaja, Stegonotus), but we never recorded consumption of toads by three snake species that often attacked toads (Boiga, Dendrelaphis, Furina: see Table 1).

4. Ingestion of a toad was more likely to be followed by predator mortality in some species than others $\left(\chi^{2}=90.94, P<0.0001\right)$. For example, slatey-grey snakes (Stegonotus cucullatus) often consumed toads, but never showed ill effects from doing so.
In contrast, all of the bluetongue skinks (Tiliqua scincoides intermedia) that ate toads, died as a result (Table 1).

5. In an interspecific comparison, larger-bodied species were more likely to attack toads (Fig. 1a; $n=47$ taxa, mean body mass vs. $\%$ attack toads, $\left.r^{2}=0.28, \quad P<0.0001\right)$. However, a predator species mean body mass was not significantly related to its probability of eating the toad after attacking it (based on the 28 species where attacks were recorded, $\left.r^{2}=0.05, P=0.24\right)$ or for it to die from toad-poisoning if it attacked a toad $(n=28$, $\left.r^{2}=0.01, P=0.66\right)$. Nonetheless, the body-mass effect on propensity to attack was strong enough to result in overall significant correlations between body mass and the probability of eating a toad (based on the full 47 species, $r^{2}=0.29, P<$ 0.0001 ; see Fig. 1b) and dying as a result $(n=47$, $r^{2}=0.18, P<0.003$; see Fig. 1c). Thus, largerbodied species may be at more risk from toad invasion, simply because they are more likely to attack toads.

\section{DISCUSSION}

Our data from encounters between reptile predators and invasive cane toads fill a significant gap in our knowledge about mechanisms of toad impact and possible population effects. Previous studies have reported the results of similar trials on other vertebrates, including native fishes (Nelson et al. 2010, 2011a,b), freshwater crocodiles (Somaweera et al. 2011), frogs (Shine et al. 2009; Greenlees et al. 2010; Nelson et al. 2010, $2011 \mathrm{a}, \mathrm{b}$ ), birds (Beckmann \& Shine 2011, Beckmann et al. 2011) and mammals (Webb et al. 2008, 2011; O'Donnell et al. 2010; Llewelyn et al. 2010a; Kaemper et al. 2013). However, relatively few squamate taxa have been studied in this respect (see Appendix S1 for a summary of published reports on responses of reptiles to invasive cane toads).

Any conclusions from our trials must be made with caution. First, sample sizes were small for almost all of the taxa (for ethical reasons), and there was substantial individual variation in predatory responses to toads even within a single predator taxon (Table 1). Within several of the taxa that we tested, some individuals seized the first toad that was offered (and died as a result) whereas conspecifics (often, collected from the same population) consistently refused toads in six successive trials, despite feeding enthusiastically on alternative prey types during intervening trials. Also, minor variation in the sizes of toads that were offered (driven by availability) may have influenced feeding responses; predators may selectively take some size-classes of toads rather than others (as has been shown in the toxin-tolerant Tropidonophis mairii: Llewelyn et al. 
Table 1. Results of trials in which recently captured lizards and snakes were offered edible-sized cane toads (Rhinella marina)

\begin{tabular}{|c|c|c|c|c|c|c|c|}
\hline Species & $\begin{array}{l}\text { No. } \\
\text { predators }\end{array}$ & $\begin{array}{c}\text { No. } \\
\text { attacked toad }\end{array}$ & $\begin{array}{l}\text { No. ate } \\
\text { toad }\end{array}$ & No. died & $\begin{array}{l}\text { Proportion } \\
\text { attacked toad }\end{array}$ & $\begin{array}{l}\text { Proportion } \\
\text { ate toad }\end{array}$ & $\begin{array}{l}\text { Proportion } \\
\text { died }\end{array}$ \\
\hline \multicolumn{8}{|l|}{ Snakes } \\
\hline \multicolumn{8}{|l|}{ Elapidae } \\
\hline Acanthophis praelongus & 74 & 51 & 42 & 17 & 0.69 & 0.57 & 0.23 \\
\hline Cryptophis pallidiceps & 1 & 0 & 0 & 0 & 0.00 & 0.00 & 0.00 \\
\hline Demansia olivacea & 5 & 0 & 0 & 0 & 0.00 & 0.00 & 0.00 \\
\hline Demansia papuensis & 10 & 8 & 5 & 7 & 0.80 & 0.50 & 0.70 \\
\hline Demansia vestigiata & 6 & 5 & 3 & 0 & 0.83 & 0.50 & 0.00 \\
\hline Furina ornata & 8 & 5 & 0 & 0 & 0.63 & 0.00 & 0.00 \\
\hline Pseudechis australis & 11 & 8 & 7 & 6 & 0.73 & 0.64 & 0.55 \\
\hline Pseudechis weigeli & 5 & 1 & 1 & 1 & 0.20 & 0.20 & 0.20 \\
\hline Pseudonaja nuchalis & 15 & 10 & 8 & 6 & 0.67 & 0.53 & 0.40 \\
\hline Suta punctata & 1 & 1 & 1 & 1 & 1.00 & 1.00 & 1.00 \\
\hline \multicolumn{8}{|l|}{ Colubridae } \\
\hline Boiga irregularis & 20 & 11 & 3 & 2 & 0.55 & 0.15 & 0.10 \\
\hline Dendrelaphis punctulata & 20 & 10 & 3 & 0 & 0.50 & 0.15 & 0.00 \\
\hline Enhydris polylepis & 20 & 9 & 8 & 9 & 0.45 & 0.40 & 0.45 \\
\hline Stegonotus cucullatus & 21 & 12 & 12 & 0 & 0.57 & 0.57 & 0.00 \\
\hline \multicolumn{8}{|l|}{ Pythonidae } \\
\hline Antaresia childreni & 27 & 10 & 6 & 4 & 0.37 & 0.22 & 0.15 \\
\hline Liasis olivaceus & 3 & 1 & 1 & 0 & 0.33 & 0.33 & 0.00 \\
\hline Morelia spilota & 5 & 5 & 4 & 4 & 1.00 & 0.80 & 0.80 \\
\hline \multicolumn{8}{|l|}{ Lizards } \\
\hline \multicolumn{8}{|l|}{ Scincidae } \\
\hline Carlia triacantha & 4 & 0 & 0 & 0 & 0.00 & 0.00 & 0.00 \\
\hline Carlia munda & 2 & 0 & 0 & 0 & 0.00 & 0.00 & 0.00 \\
\hline Ctenotus burbidgei & 2 & 0 & 0 & 0 & 0.00 & 0.00 & 0.00 \\
\hline Ctenotus inornatus & 9 & 0 & 0 & 0 & 0.00 & 0.00 & 0.00 \\
\hline Ctenotus robustus & 37 & 9 & 7 & 1 & 0.24 & 0.19 & 0.03 \\
\hline Ctenotus saxatilis & 6 & 0 & 0 & 0 & 0.00 & 0.00 & 0.00 \\
\hline Ctenotus tantillus & 5 & 0 & 0 & 0 & 0.00 & 0.00 & 0.00 \\
\hline Ctenotus pantherinus & 2 & 0 & 0 & 0 & 0.00 & 0.00 & 0.00 \\
\hline Cyclodomorphus melanops & 1 & 0 & 0 & 0 & 0.00 & 0.00 & 0.00 \\
\hline Glaphyromorphus brongersmai & 3 & 0 & 0 & 0 & 0.00 & 0.00 & 0.00 \\
\hline Glaphyromorphus isolepis & 20 & 11 & 3 & 2 & 0.55 & 0.15 & 0.10 \\
\hline Tiliqua scincoides intermedia & 29 & 11 & 7 & 7 & 0.38 & 0.24 & 0.24 \\
\hline \multicolumn{8}{|l|}{ Agamidae } \\
\hline Amphibolurus gilberti & 1 & 0 & 0 & 0 & 0.00 & 0.00 & 0.00 \\
\hline Chelosania brunnea & 1 & 0 & 0 & 0 & 0.00 & 0.00 & 0.00 \\
\hline Diporiphora sp. & 4 & 3 & 1 & 0 & 0.75 & 0.25 & 0.00 \\
\hline Diporiphora albilabris & 1 & 0 & 0 & 0 & 0.00 & 0.00 & 0.00 \\
\hline Diporiphora bennetti & 7 & 1 & 1 & 1 & 0.14 & 0.14 & 0.14 \\
\hline Diporiphora superba & 1 & 0 & 0 & 0 & 0.00 & 0.00 & 0.00 \\
\hline Diporiphora magna & 6 & 0 & 0 & 0 & 0.00 & 0.00 & 0.00 \\
\hline Tympanocryptis centralis & 2 & 0 & 0 & 0 & 0.00 & 0.00 & 0.00 \\
\hline \multicolumn{8}{|l|}{ Pygopodidae } \\
\hline Lialis burtonis & 1 & 0 & 0 & 0 & 0.00 & 0.00 & 0.00 \\
\hline \multicolumn{8}{|l|}{ Varanidae } \\
\hline Varanus acanthurus & 14 & 7 & 5 & 2 & 0.50 & 0.36 & 0.14 \\
\hline Varanus glauerti & 10 & 8 & 4 & 2 & 0.80 & 0.40 & 0.20 \\
\hline Varanus glebopalma & 5 & 4 & 4 & 3 & 0.80 & 0.80 & 0.60 \\
\hline Varanus gouldii & 5 & 4 & 3 & 1 & 0.80 & 0.60 & 0.20 \\
\hline Varanus mertensi & 4 & 4 & 2 & 4 & 1.00 & 0.50 & 1.00 \\
\hline Varanus mitchelli & 11 & 11 & 4 & 10 & 1.00 & 0.36 & 0.91 \\
\hline Varanus scalaris & 5 & 4 & 3 & 2 & 0.80 & 0.60 & 0.40 \\
\hline Varanus storri & 4 & 0 & 0 & 0 & 0.00 & 0.00 & 0.00 \\
\hline Varanus tristis & 4 & 4 & 3 & 1 & 1.00 & 0.75 & 0.25 \\
\hline
\end{tabular}

The table shows numbers of predators tested, and numbers that attacked and ate toads, and that died as a result. The final columns show those same numbers as proportions of the total number of predators tested per species. 

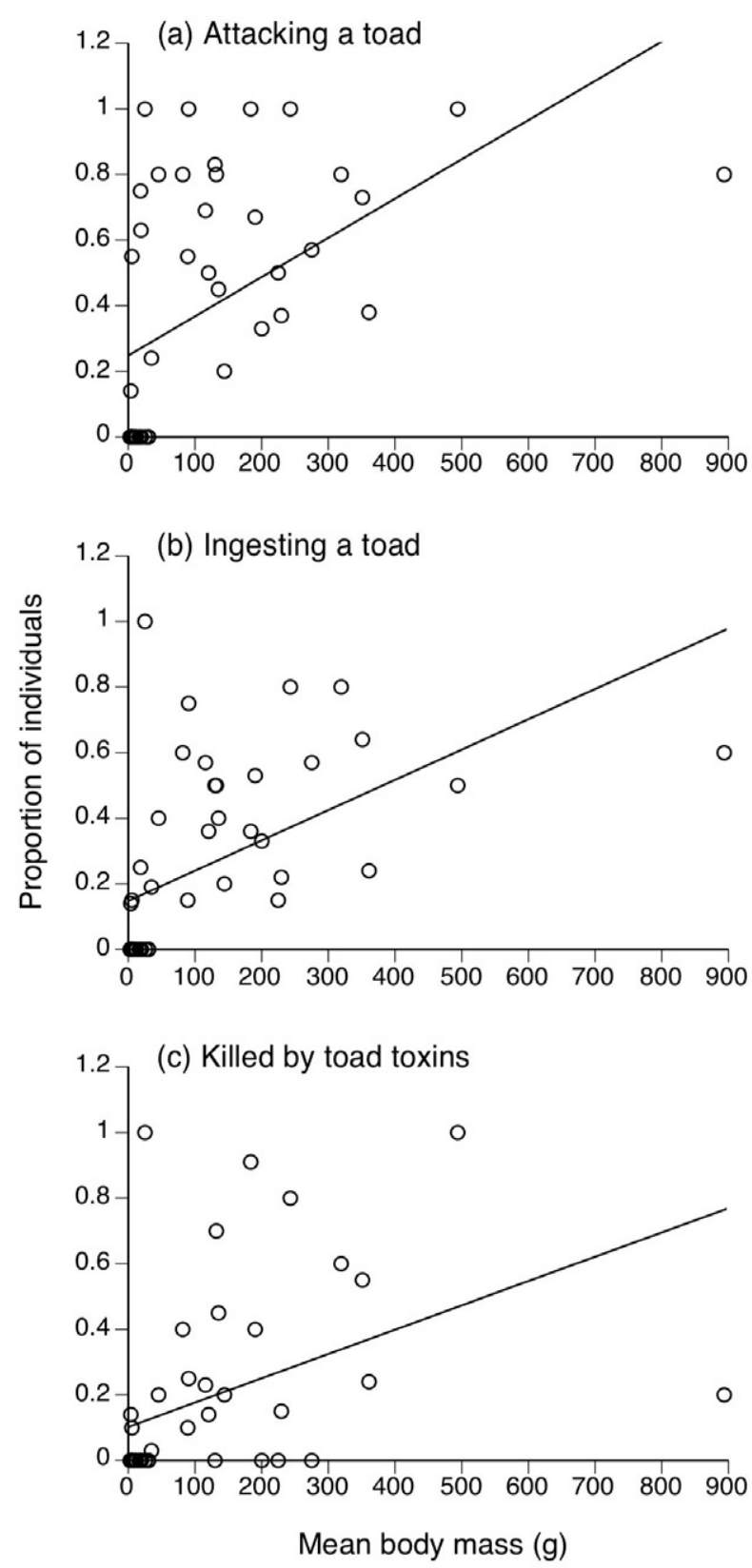

Fig. 1. Interspecific relationships between mean adult body mass of a predatory reptile species, and the proportion of individuals that attacked and consumed cane toads in laboratory trials, and that died as a result of ingesting the toxic toads. The lines show linear regressions fitted to these data.

2012). Thirdly, captivity may have influenced predator responses, either by changing hunger levels (for specimens that did not feed readily in captivity), curtailing usual predatory responses (e.g. through captivityinduced stress) or encouraging defensive rather than feeding strikes (if captivity, or the continued close proximity of toads, stimulated defensive behaviour).

Nonetheless, our results have some robust implications for toad impact. First, some individual predators are likely to be killed by toad-toxin ingestion even in species that usually do not attack or ingest toads. In our study, this was true even for occasional specimens of relatively small-bodied lizard species that would be unlikely to ingest vertebrate prey items in the wild (e.g. Ctenotus, Diporiphora: see Table 1). Hence, anecdotal observations of dead predators in the wild after toad invasion may tell us very little about population-level impacts of this invasive anuran (see also Doody et al. 2009; Shine 2010). For example, although dietary analyses (Shine \& Lambeck 1989) and feeding studies on captive frillneck lizards (Chlamydosaurus kingii) suggested that these iconic lizards will not eat anurans (including toads), and population studies showed no consistent decline in lizard numbers after toad invasion (Ujvari et al. 2011), we found a freshly dead adult male lizard of this species in Kununurra, WA, shortly after toads arrived in this region. The lizard contained a freshly ingested cane toad (Appendix S2) but was otherwise uninjured, strongly suggesting that the toad's toxins were responsible for the predator's death. Similarly, there are occasional reports of fatal toadpoisoning even in snake species that are physiologically resistant to bufotoxins, presumably because that tolerance is not absolute (Llewelyn et al. 2009) and individual predators occasionally ingest toads whose toxin content exceeds the predator's tolerance (e.g. S. cucullatus - Brown et al. 2011; T. mairii - Ingram \& Covacevich 1990). Natural selection thus may favour 'toad-smart' traits even in taxa that are not affected at the population level by toad invasion.

General patterns in responses of reptile predators to toads (Table 1) are consistent with previous analyses (e.g. Shine 2010) in revealing variation at the familial and species level, as well as among individuals within species. In general, elapid snakes and varanid lizards appear to be more vulnerable to toads than are species within the other families studied. The primary reason for that disparity is that elapids and varanids were more likely to attack toads than were species from most of the other squamate families tested, and typically consumed toads after they killed them. In contrast, most scincid and agamid lizards did not attack toads; and most colubrid snakes either did not eat toads they had killed (Boiga, Dendrelaphis) or were able to tolerate the toad's toxins (Stegonotus). Extensive data on another colubrid, T. mairii, show that it is even more resistant to toad toxin than are Stegonotus (see Appendix S1). The apparent susceptibility of the aquatic homalopsine colubrid Enhydris polylepis (Table 1) warrants further study. To our knowledge, there are no published data on population-level impacts of cane toads on this species.

A species body size as well as its familial identity affected the likelihood of a predator killing and eating a toad, and of dying as a result (Fig. 1). Larger species were at more risk, because they were more 
likely to attack a toad (Fig. 1a). The consequences of launching such an attack presumably vary with many factors; for example, an adult estuarine crocodile (Crocodylus porosus) is so large that it is unlikely to be at risk even if it consumes a large toad, because the prey size (and thus, toxin content) is so low relative to predator size (Smith \& Phillips 2006). Outcomes of encounters are further complicated by speciesspecific differences in maximal ingestible prey sizes of predators, and in the allometry of toxin content relative to toad body size in toads (Phillips \& Shine 2006b). Broadly, the predators most at risk from toad invasion appear to be those that are prepared to attack relatively large prey, do not distinguish between toads and native frogs, are not physiologically pre-adapted to tolerate bufotoxins, and do not readily learn conditioned taste aversion.

Unfortunately, these mechanistic influences on predator vulnerability do not translate in any straightforward way into the magnitude of ecological (population-level) impacts of toad invasion. Thus, for example, detailed radio-tracking studies documented high mortality of death adders ( $A$. praelongus) due to toad ingestion, whereas surveys at an adjacent site revealed a significant increase rather than decrease in adder abundance over the same period (Phillips et al. 2010; Brown et al. 2011). These conflicting trends reflect the importance of indirect effects, mediated via toad-induced poisoning of apex predators (large varanid lizards) that facilitated mesopredator release (Brown et al. 2011). However, our data clarify the mechanisms underlying persistence of toxinvulnerable arboreal colubrid snakes (Boiga and Dendrelaphis) in tropical Australia; these snakes can readily distinguish between toads and frogs, and do not attempt to consume toads. Thus, lethal toxic ingestion is unlikely to be a high risk for these species. Based on our limited sample sizes, the same may be true for at least one species of elapid snake (F. ornata).

In conclusion, our laboratory trials show that a surprisingly wide taxonomic range of squamate reptile predators are vulnerable to the invasion of cane toads, although for most species the risk is minor. That ability to co-exist with toads is driven by a diverse array of traits, that differs among species. A frog-eating reptile species may be largely unaffected by toad invasion because of a reluctance to consume toads, an innate ability to rapidly distinguish between toads and frogs, an ability to learn taste aversion and/or an ability to tolerate toad toxins. Even in species that are at high risk due to toad-poisoning, however, the populationlevel consequences of that vulnerability may be reduced by offsetting indirect effects (Brown et al. 2011). The end result is that even in this intensively studied system, an understanding of toad impacts requires information on predator behaviour as well as population-level effects of toad arrival.

\section{ACKNOWLEDGEMENTS}

We thank Michelle Franklin, Nilu Somaweera and Georgia Ward-Fear for conducting many of the trials, and Bill Stewart, Lauren Brown, Kate George and Simon Cherriman for assistance in catching study animals. We thank the University of Sydney Animal Care and Ethics Committee for responsibly considering the difficult issue of balancing animal-welfare concerns against the need for conservation-relevant information, and approving the experiments. The study was funded by the Australian Research Council and the Department of Parks and Wildlife (formerly the Department of Environment and Conservation).

\section{REFERENCES}

Beckmann C., Crossland M. R. \& Shine R. (2011) Responses of Australian wading birds to a novel toxic prey type, the invasive cane toad Rhinella marina. Biol. Invasions 13, 2925-34.

Beckmann C. \& Shine R. (2011) Toad's tongue for breakfast: exploitation of a novel prey type, the invasive cane toad, by scavenging raptors in tropical Australia. Biol. Invasions 13, 1447-55.

Brown G. P., Greenlees M. J., Phillips B. L. \& Shine R. (2013) Road transect surveys do not reveal any consistent effects of a toxic invasive species on tropical reptiles. Biol. Invasions 15, 1005-15.

Brown G. P., Phillips B. L. \& Shine R. (2011) The ecological impact of invasive cane toads on tropical snakes: field data do not support predictions from laboratory studies. Ecology 92, 422-31.

Doody J. S., Green B., Rhind D., Castellano C. M., Sims R. \& Robinson T. (2009) Population-level declines in Australian predators caused by an invasive species. Anim. Conserv. 12, 46-53.

Greenlees M., Phillips B. L. \& Shine R. (2010) Adjusting to a toxic invader: native Australian frog learns not to prey on cane toads. Behav. Ecol. 21, 966-71.

Greenlees M. J. \& Shine R. (2011) Impacts of eggs and tadpoles of the invasive cane toad (Bufo marinus) on aquatic predators in tropical Australia. Austral Ecol. 36, 53-8.

Hagman M., Phillips B. L. \& Shine R. (2009) Fatal attraction: adaptations to prey on native frogs imperil snakes after invasion of toxic toads. Proc. R. Soc. B 276, 2813-18.

Ingram G. J. \& Covacevich J. (1990) Tropidonophis mairii vs. Bufo marinus. Mem. Queensl. Mus. 29, 396.

Kaemper W., Webb J. K., Crowther M. S., Greenlees M. J. \& Shine R. (2013) Behaviour and survivorship of a dasyurid predator (Antechinus flavipes) in response to encounters with the toxic and invasive cane toad (Rhinella marina). Aust. Mammal. 35, 136-43.

Llewelyn J., Bell K., Schwarzkopf L., Alford R. A. \& Shine R. (2012) Ontogenetic shifts in a prey's chemical defence influence feeding responses of a snake predator. Oecologia 169, 965-73.

Llewelyn J., Phillips B. L., Brown G. P., Schwarzkopf L., Alford R. A. \& Shine R. (2011) Adaptation or preadaptation: why are keelback snakes (Tropidonophis mairii) less vulnerable to invasive cane toads (Bufo marinus) than are other Australian snakes? Evol. Ecol. 25, 13-24.

(C) 2013 The Authors

doi:10.1111/aec.12102
Austral Ecology (C) 2013 Ecological Society of Australia 
Llewelyn J., Phillips B. L. \& Shine R. (2009) Sublethal costs associated with the consumption of toxic prey by snakes. Austral Ecol. 34, 179-84.

Llewelyn J., Schwarzkopf L., Alford R. \& Shine R. (2010b) Something different for dinner? Responses of a native Australian predator (the keelback snake) to an invasive prey species (the cane toad). Biol. Invasions 12, 1045-51.

Llewelyn J., Schwarzkopf L., Phillips B. L. \& Shine R. (2013) After the crash: how do predators adjust following the invasion of a novel toxic prey type? Austral Ecol. (in press). doi: 10.1111/aec.12058.

Llewelyn J., Webb J. K., Schwarzkopf L., Alford R. \& Shine R. (2010a) Behavioural responses of carnivorous marsupials (Planigale maculata) to toxic invasive cane toads (Bufo marinus). Austral Ecol. 35, 560-7.

Nelson D., Crossland M. R. \& Shine R. (2010) Indirect ecological impacts of an invasive toad on predator-prey interactions among native species. Biol. Invasions 12, 3363-9.

Nelson D. W. M., Crossland M. R. \& Shine R. (2011a) Behavioural responses of native predators to an invasive toxic prey species. Austral Ecol. 36, 605-11.

Nelson D. W. M., Crossland M. R. \& Shine R. (2011b) Foraging responses of predators to novel toxic prey: effects of predator learning and relative prey abundance. Oikos 120, 152-8.

O’Donnell S., Webb J. K. \& Shine R. (2010) Conditioned taste aversion enhances the survival of an endangered predator imperiled by a toxic invader. F. Appl. Ecol. 47, 558-65.

Phillips B., Brown G. P. \& Shine R. (2003) Assessing the potential impact of cane toads (Bufo marinus) on Australian snakes. Conserv. Biol. 17, 1738-47.

Phillips B. L., Greenlees M. J., Brown G. P. \& Shine R. (2010) Predator behaviour and morphology mediates the impact of an invasive species: cane toads and death adders in Australia. Anim. Conserv. 13, 53-9.

Phillips B. L. \& Shine R. (2006a) An invasive species induces rapid adaptive change in a native predator: cane toads and black snakes in Australia. Proc. R. Soc. B 273, 1545-50,

Phillips B. L. \& Shine R. (2006b) Allometry and selection in a novel predator-prey system: Australian snakes and the invading cane toad. Oikos 112, 122-30.

Phillips B. L. \& Shine R. (2007) When dinner is dangerous: toxic frogs elicit species-specific responses from a generalist snake predator. Am. Nat. 170, 936-42.

Pimentel D., Lach L., Zuniga R. \& Morrison D. (2000) Environmental and economic costs of nonindigenous species in the United States. Bioscience 50, 53-65.

Price-Rees S., Webb J. K. \& Shine R. (2011) School for skinks: can conditioned taste aversion enable Bluetongue Lizards (Tiliqua scincoides) to avoid toxic cane toads (Rhinella marina) as prey? Ethology 117, 749-57.

Price-Rees S. J., Brown G. P. \& Shine R. (2010) Predation on toxic cane toads (Bufo marinus) may imperil bluetongue lizards (Tiliqua scincoides intermedia, Scincidae) in tropical Australia. Wildl. Res. 37, 166-73.

Shine R. (2010) The ecological impact of invasive cane toads (Bufo marinus) in Australia. Q. Rev. Biol. 85, 253-91.

Shine R., Greenlees M., Crossland M. R. \& Nelson D. (2009) The myth of the toad-eating frog. Front. Ecol. Environ. 7, 359-61.

Shine R. \& Lambeck R. (1989) Ecology of frillneck lizards Chlamydosaurus kingii (Agamidae) in tropical Australia. Aust.Wildl. Res. 16, 491-500.

Smith J. \& Phillips B. (2006) Toxic tucker: the potential impact of cane toads on Australian reptiles. Pac. Conserv. Biol. 12, $40-9$.

Somaweera R., Shine R., Webb J., Dempster T. \& Letnic M. (2013) Why does vulnerability to toxic invasive cane toads vary among populations of Australian freshwater crocodiles? Anim. Conserv. 16, 86-96.

Somaweera R., Webb J. K., Brown G. P. \& Shine R. (2011) Hatchling Australian freshwater crocodiles rapidly learn to avoid toxic invasive cane toads. Behaviour 148, 501-17.

Ujvari B., Shine R. \& Madsen T. (2011) Detecting the impact of invasive species on native fauna: cane toads (Bufo marinus), frillneck lizards (Chlamydosaurus kingii), and the importance of spatial replication. Austral Ecol. 36, 126-30.

Webb J. K., Brown G. P., Child T., Greenlees M. J., Phillips B. L. \& Shine R. (2008) A native dasyurid predator (common planigale, Planigale maculata) rapidly learns to avoid toxic cane toads. Austral Ecol. 33, 821-9.

Webb J. K., Pearson D. \& Shine R. (2011) A small dasyurid predator (Sminthopsis virginiae) rapidly learns to avoid a toxic invader. Wildl. Res. 38, 726-31.

Webb J. K., Shine R. \& Christian K. A. (2005) Intraspecific niche partitioning in a native predator may influence its response to invasion by a toxic prey species. Austral Ecol. 30, 201-9.

Wootton J. T. (1994) The nature and consequences of indirect effects in ecological communities. Annu. Rev. Ecol. Syst. 25, 443-66.

\section{SUPPORTING INFORMATION}

Additional Supporting Information may be found in the online version of this article at the publisher's web-site:

Appendix S1. The results of published studies on the responses of naïve Australian reptile predators to cane toads (Rhinella marina).

Appendix S2. Dissection of an adult male frillneck lizard (Chlamydosaurus kingii) found dead in Kununurra, WA in April 2011. 